\title{
Research on Digital Humanities Education Practice and Library Support Strategies in Universities
}

\author{
Hongqiu Liu \\ Library, Zaozhuang University, Zaozhuang, Shandong277160, China \\ Email:lhq_724@126.com
}

\begin{abstract}
With the rise of digital humanities in the world, libraries are not only an important institution supporting digital humanities research, but also an important part of participating in digital humanities education. This article reviews the digital humanities education practices in some foreign universities and libraries, and gives six rational suggestions for the support of digital humanities education practices in university libraries, including the provision of digital humanistic special services, active participation in digital humanities research in institutions, participating in digital humanities teaching practices, establishing digital humanities research centers, strengthening data management, and providing technical support.
\end{abstract}

Keywords: humanities, digital humanities, university library, educational practice

\section{INTRODUCTION}

The concept of "Digital Humanities" was born in 1949. Its original prototype was "Humanities Computing" [1]. Early digital humanities were mainly defined as a supplementary research method for quantitative analysis of humanities. In recent years, with the application of computer science and technology in the humanities and social sciences, digital technology and computer computing have been used to solve problems in the humanities. Digital Humanities has attracted widespread attention from humanists, computer scholars, and the library community worldwide. Scholars recognize the importance of digital humanities education. After entering the mid-to-late 1990s, with the gradual maturity of digital humanities, digital humanities majors gradually appeared in higher education in the United States, Britain, Canada and other countries. King's College London has established a Digital Humanities College to train digital humanities, masters and doctors. University of Victoria offers a graduate program in digital humanities under the English Department. The Swiss Federal Institute of Technology offers a master's degree in digital humanities at the Faculty of Humanities. In China, digital humanities research centers have been established at Wuhan University, Peking University, Nanjing University, Renmin University of China, and Qufu Normal University to carry out digital humanities theoretical research, practical exploration, humanities project research, talent training, and academic exchange activity.

For the library, the proposal of digital humanities education provides a good opportunity for its involvement in interdisciplinary education activities, mutual cooperation and integration with the humanities and computer fields. Using the library to intervene in digital humanities education can not only accumulate a certain number of teachers and teaching experience for digital humanities education, but also provide a practical basis for gradually exploring a subject system suitable for digital humanities education in Chinese universities [2]. But how should libraries get involved and assume the corresponding digital humanities education role? Based on this problem, this article elaborates the practice of digital humanities education in universities, and analyzes the countermeasures of university libraries' further participation in digital humanities education.

\section{DIGITAL HUMANITIES EDUCATION PRACTICE IN UNIVERSITIES}

Digital humanities education can be divided into two categories according to their professional level. First, the promotion of digital humanities. It is mainly to help users learn new research paradigms, methodologies and the use of various tools in digital humanities, and to discuss and analyze the research results to meet the requirements of the current scientific research environment. The second is a specialized degree course. That is, the establishment of digital human texts, masters, and doctorates, and a systematic and comprehensive study of digital humanities, the purpose is to train digital humanities research scholars. Digital humanities research in foreign countries is more indepth and has been carried out earlier. A number of digital humanities research centers have been established around the world, mainly concentrated in developed countries such as Europe, the United States, and Japan. Among them are: Stanford University Humanities Lab, MIT Hyper studio, and University of Illinois' Scientific Academic Information Research Center, etc. And formed an international organization: The Alliance of Digital Humanities Organizations (ADHO). Digital humanities education in foreign countries generally covers many subject areas, such as philosophy, history, literature, library and information science, linguistics, art, and anthropology. In the United States, digital humanities courses in universities include 
certification courses, special courses, minor courses, and elective courses. Most of the courses are set in the computer science and technology major of the computer school and the library information and literature major of the information school. High practical skills are required, and students' ability to master tools, technologies, and selfdeveloped projects is emphasized [3]. Digital humanities courses in Europe include the entire undergraduate, master's and doctoral stages, of which computer science, linguistics, literature, art, library science and information science are the main positions of digital humanities courses.

In China, there is currently no digital humanities major, but a number of digital humanities research centers have been established to carry out digital humanities theoretical research, practical exploration, humanities project research, talent training, and academic exchanges. Wuhan University's Center for Digital Humanities was established in 2011. It is the first digital humanities research center in Mainland China. The center is an interdisciplinary research platform dedicated to exploring the production and dissemination of various digital information technologies in the humanities, including project practice, teaching and research results transformation. Peking University has established a "Digital Humanities Workshop" to exchange and discuss certain topics in humanities and technology. In order to meet the new requirements of Confucianism and Chinese cultural communication methods in the digital age, Qufu Normal University also established a Digital Humanities Research Center in 2018, which is attached to the School of Foreign Languages.

\section{UNIVERSITY LIBRARIES' PRACTICE IN SUPPORTING DIGITAL HUMANITIES EDUCATION}

University libraries shoulder the mission of serving lifelong learning and promoting academic communication and dissemination. Digital humanities education is an inherent requirement of its role, mission and functional positioning.

\subsection{It Is An Inevitable Trend for University Libraries to Launch Digital Humanistic Services}

The increasingly mature digital humanities environment, the development needs of libraries to keep up with the times, and the potential benefits of carrying out digital humanities education-related activities have led libraries to carry out various forms of digital humanities education activities [4]. (1) Supporting digital humanities education is the role and mission of university libraries.

Digital humanities education requires the protection of space, resources, and infrastructure. University libraries are an indispensable institution for teacher and student learning and scientific research. They have five advantages: space, collection resources, digital technology, librarians, and services. Libraries can provide space protection for digital humanities research and digital humanities education. The library has a large number of paper collections and digital collections, which is the support of resources and projects for digital humanities education. The development of digital libraries can provide technical support for the development of digital humanities; the professional skills and role of librarians require that they keep abreast of the development of the times and access to the subject knowledge of emerging fields; services have always been the central work of libraries, and libraries provide digital humanistic services, which can provide digital Humanities education provides strong support.

(2) The potential motivation of university library's digital humanities education activities.

The development of digital humanities education is a huge challenge faced by the humanities under the information technology environment. It also promotes academic exchanges in the context of data-intensive scientific research and improves the digital literacy and data literacy of users. Digital humanities education in libraries is a very good way to popularize data literacy. The library conducts digital humanities education for specific users, which is in line with the development of the times and its requirements. At the same time, libraries carrying out digital humanities education can also strive for more development opportunities for themselves. Digital humanities education has expanded the scope of library education and training, which can further promote interdisciplinary academic exchanges, establish closer ties with humanists and computer scholars, and improve the ability of libraries to keep up with the times and sustainable development. Improve the status of universities to strive for better conditions for their own development.

\subsection{The Practice of University Libraries in Supporting Digital Humanities Education}

Relevant activities carried out by university libraries include the following aspects:

(1) The establishment of a digital humanities research center.

To use existing resources to support the development of digital humanities projects and provide an expanded platform for their development, which will become a new hotspot for academic exchanges and teaching research. Such as Columbia University Digital Humanities Center and University of Alabama Digital Humanities Center. The Columbia University Digital Humanities Center is located in the Butler Library. It is designed to assist Columbia University teachers and students in integrating text, bibliography, image and sound materials with their research, learning and teaching, and to support scientific users in the humanities to use digital text, static and dynamic image and other related information. The University of Alabama's Digital Humanities Center is also located in the library. The library provides related topic guidance, information inquiry, reference and expert services, and conduct interdisciplinary cooperation in teaching and research activities. Peking 
University, which has a tradition of humanities and social sciences, recognizes the unique and irreplaceable advantages of digital technology, has established a "Digital Humanities Workshop" in its library to exchange and discuss certain topics in humanities and technology.

(2) Participate in digital humanities teaching practice.

The Stanford University Library has a digital humanities librarian who is responsible for digital humanities teaching and research tasks. The course involves the use of digital humanities research methods and tools [5]. The UCLA Library plays a part of the subject education role in digital humanities services, conducts targeted digital humanities literacy training, and cooperates with other digital humanities institutions in the school to develop course training. Nanjing Medical University uses the library to carry out medical digital humanities teaching practice [6].

(3) Other forms of practical activities.

These include setting up a professional space for digital humanities education, building a digital humanities education promotion network platform, creating a digital humanities education resource library, and hosting international humanities international seminars. For example, the "Library and Digital Humanities" international symposium hosted by the Shenzhen University City Library discussed "Higher Education and Digital Humanities", and many experts shared the practice of digital humanities in libraries at home and abroad [7] .

\section{RESEARCH ON THE SUPPORTING STRATEGIES OF UNIVERSITY LIBRARIES UNDER THE BACKGROUND OF DIGITAL HUMANITIES EDUCATION}

It can be seen from the practice of digital humanities education that libraries have always played an important role in digital humanities education. In view of the development trend of digital humanities research and the current status of libraries, university libraries can support digital humanities education with the following six aspects: (1) Integrate various resources and provide digital humanistic special services.

With the change of the information environment, various functions of the library have also undergone major changes. It has become the third space that places equal emphasis on social communication and academic research, but its functions in terms of information collection, organization and resource acquisition have not weakened. The library itself has a large number of information resources such as databases. These resources are an important basis for digital humanities research, and libraries can provide them with various types of information resources. At the same time, the library can also integrate resources, build a digital humanities education resource library, and carry out digital humanities special services [8].

(2) Multilateral cooperation and actively participate in digital humanities research in institutions.

At present, there are not many digital humanities researches in China, which are basically concentrated in universities or research institutes, which provides opportunities for library participation. Libraries should seize the opportunity, cooperate with multiple parties, and actively embed themselves in the digital humanities research of the institution, grasp the development trend of digital humanities in general, provide sound infrastructure, and create a platform for digital humanities research and development, which not only serves digital Humanities research should also develop into a universal platform to provide services for more digital research. At the same time, it enriches digital collections, and assists scientific researchers to create digital collections and multimedia materials, ensuring users' data acquisition and providing reference consulting.

(3) Cultivate professional talents and participate in digital humanities teaching practice.

Digital humanities research places high requirements on the quality of librarians, not only with a professional background, but also with a rich knowledge reserve, which should conform to the existing academic communication model. Digital humanities research is an interdisciplinary research field, and the prerequisite for librarians to play a role in it is to have background knowledge of related disciplines. The library can optimize the combination of personnel with different discipline structures and abilities in the library, form a digital humanities service team, provide services for the digital humanities project of the unit, and actively participate in the practice of digital humanities teaching.

(4) Establish digital humanities research center according to local conditions.

In addition to information resources, the library can also create a dedicated digital humanities research space to meet the needs of digital humanities research or related projects, and provide the necessary research environment for digital humanities research, allowing researchers to carry out digital humanities research more conveniently and efficiently. Libraries can also focus on building a digital humanities research center. Based on the specific problems existing in digital humanities research, they can display and recommend relevant information about their digital humanities research projects, and provide interdisciplinary talent docking services. Projects and talent match faster and more effectively. At the same time, the Digital Humanities Research Center can also integrate the needs of humanities scholars and digital technicians to incubate new digital humanities research projects and become a good communication platform.

(5) Strengthen data management and promote the dissemination of digital humanities results.

Scientific research data management is an important function of the library. Its purpose is to preserve all types of data generated during the scientific research process and provide continuous services for its redevelopment and utilization. In the process of digital humanities research, a large amount of valuable scientific research data will be generated. These scientific research data have important reuse values for future digital humanities research. Therefore, libraries can provide corresponding scientific data management services. At the same time, libraries can 
[4] Y. Xiaowen, Countermeasures for Digital Humanities Education in University Libraries in China[J]. Library Tribune, 2018, 038(011), pp. 35-43.

[5] D. Jingda, L. Ying, Digital Humanities Education Practice of Stanford University and Library Support Services, Agricultural Library and Information, 2019,31(11), pp. 15-22. DOI: 10.13998/j.cnki.issn10021248.2019.10.19-0832

[6] Y. Xiaowen, Digital Humanities Education Under ACRL's Framework for Information Literacy for Higher Education, Library Tribune, 2018, (12), pp. 61-69.

[7] Z. Ling, Review of the Library and Digital Humanities Forum, Journal of Academic Libraries, 2018, 36 (2), pp. 5-10. DOI: 10.16603/j.issn10021027.2018.02.001

[8] Z. Chen, Present Status and Development Path of Digital Humanities Construction of Libraries in Big Data Era, Library Work and Study, 2018, (6), pp. 50-53. DOI: 10.16384/j.cnki.lwas.2018.06.010

Digital humanities is a new field of humanities research, which has an important role and influence on cultural heritage and innovation. At present, the development of digital humanities is facing opportunities and challenges. As an important institution for resource storage and cultural dissemination, university libraries can actively participate in digital humanities education practice by virtue of rich literature resources, advanced technology and equipment, and highly-skilled personnel. The library should provide an appropriate research environment and services for the digital humanities of the institution, and work with researchers to promote the development of digital humanities in a further direction.

\section{REFERENCES}

[1] M. G. Kirschenbaum, What is digital humanities and what's it doing in english departments?, Ade Bulletin, 2010, pp. 55-61. DOI: 10.1632/ade.150.55, ISSN 00010898

[2] Z. Hongyan, J. Sha, Research on Education Mode of Digital Humanities in Chinese Universities, Journal of The Sichuan Society for Library Science,2019, (06), pp. 85-88.

[3] X. Xiaojuan, H. Ying, Z. Yuxiang, X. Jianfei, Foreign Digital Humanities Courses-On the Curriculum and Talent Training of Chinese Digital Humanities Courses. Library Tribune,2018,38(07), pp. 1-11.4.1.
[9] W. Haigui, Analysis of Evolution Path of Digital Humanities in China and Support Strategy of Library, Library Work and Study, 2019, (10), pp. 106-113. DOI: 10.16384/j.cnki.lwas.2019.10.015 